\title{
Comparing the first trimester and second trimester fifty grams oral glucose tolerance test values in gestational diabetes mellitus
}

\author{
${ }^{1}$ Hasan TURAN \\ '2Zafer BÜTÜN \\ 'Sinan ERDOĞAN \\ " ${ }^{\mathrm{E}}$ bru ÇÖĞENDEZ \\ (D) ${ }^{5}$ Erdal KAYA
}

${ }^{1}$ Department of Obstetrics and Gynecology, Health Sciences University İstanbul Başakşehir Çam and Sakura City Hospital, İstanbul, Turkey

${ }^{2}$ Department of Obstetrics and Gynecology, Eskişehir City Hospital, Eskişehir, Turkey

${ }^{3}$ Department of Obstetrics and Gynecology, İskenderun Gelişim Hospital, Hatay, Turkey

${ }^{4}$ Department of Obstetrics and Gynecology, Health Sciences University Zeynep Kamil Women and Children Diseases Training and Research Hospital, İstanbul, Turkey

${ }^{5}$ Department of Obstetrics and Gynecology, Health Sciences University Ümraniye Training and Research Hospital, İstanbul, Turkey
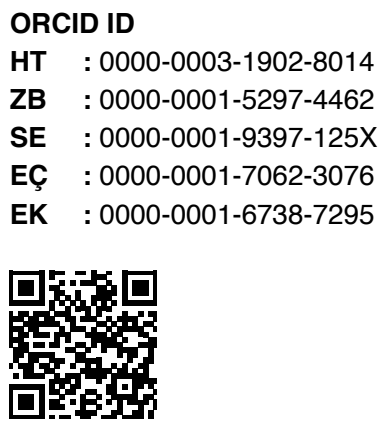

\begin{abstract}
Objective: The present study aimed to assess the results of pregnant women who have been applied a $50 \mathrm{~g}$ oral glucose tolerance test (OGTT) in the first and second trimesters and investigate this method's role in the diagnosis of gestational diabetes mellitus (GDM) and risk factors associated with this disease.
\end{abstract}

Material and Methods: This retrospective study was performed on 153 pregnant women who were admitted to our hospital's antenatal clinics between March 2011 and August 2011. Fifty grams OGTT was applied to the same pregnant women both in the $1^{\text {st }}$ trimester (between $8^{\text {th }}$ and $14^{\text {th }}$ weeks) and second trimester (between $24^{\text {th }}$ and $28^{\text {th }}$ weeks); values of the test results were then compared. A $100 \mathrm{~g}$ OGTT diagnostic test was performed on those with a $50 \mathrm{~g}$ OGTT value of $\geq 140 \mathrm{mg} / \mathrm{dl}$ in both trimesters. The study patients were divided into two groups as non-GDM and GDM based on venous plasma glucose values measured $1 \mathrm{~h}$ after $50 \mathrm{~g}$ of oral glucose load given. The non-GDM group consisted of those with plasma glucose levels $<140 \mathrm{mg} /$ $\mathrm{dl}$ and plasma glucose levels between $140 \mathrm{mg} / \mathrm{dl}$ and 200mg/dl, GDM group plasma glucose levels $\geq 200 \mathrm{mg} / \mathrm{dl}$. First trimester and second-trimester OGTT values and possible risk factors for GDM (age, gravida, parity, number of abortions, smoking, a previous GDM history, etc.) were compared between non-GDM and GDM groups.

Results: GDM, diagnosed in $4.5 \%$ (7) in the first trimester (between $8^{\text {th }}$ and $14^{\text {th }}$ weeks) and $6.5 \%(10)$ second trimester, was detected in $11 \%$ (17) of 153 pregnant women in the present study. GDM, diagnosed in $41.2 \%$ (7 patients) in the first trimester and $58.8 \%$ (10 patients) second trimester, was found with a higher rate in pregnant women over 30 years $(p=0.000<0.05)$. The mean fasting blood glucose (FBG) level was 96 $\mathrm{mg} / \mathrm{dl}$ in the GDM group and $83 \mathrm{mg} / \mathrm{dl}$ in the non-GDM group, with a statistically significant difference, which existed $(p<0.05)$. The mean $50 \mathrm{~g}$ OGTT value was $170 \mathrm{mg} /$ $\mathrm{dl}$ in pregnant women diagnosed with GDM in the first trimester, and it was $140 \mathrm{mg} / \mathrm{dl}$ in those diagnosed in the second trimester, with this difference was considered statistically different $(p<0.05)$. Age, parity, a family history of $D M, F B G$, a previous GDM history, gravida, a previous macrosomia history, and a previous history of preeclampsia were determined as risk factors that significantly increase the risk of GDM $(p<0.05)$. The half of patients was diagnosed with GDM in the early period of pregnancy. In the present study, $41.2 \%$ of cases were diagnosed in the first trimester and $58.8 \%$ in the

Cite this article as: Turan H, Bütün Z, Erdoğan S, Çöğendez E, Kaya E. Comparing the first trimester and second trimester fifty grams oral glucose tolerance test values in gestational diabetes mellitus. Zeynep Kamil Med J 2021;52(1):1-9.

Received: July 28, 2020 Accepted: February 02, 2021 Online: April 05, 2021

Correspondence: Hasan TURAN, MD. Sağlık Bilimleri Üniversitesi, İstanbul Başakşehir Çam ve Sakura Şehir Hastanesi, Kadın Hastalıkları ve Doğum Kliniği, İstanbul, Turkey.

Tel: +90 2129096000 - 30760 e-mail: hasanturan@gmail.com

๑) Copyright 2021 by Zeynep Kamil Medical Journal - Available online at www.zeynepkamilmedj.com 
second trimester. In general, the patients diagnosed in the first trimester were those being under risk in terms of GDM. According to the present study, it is recommended that the pregnant women should be scanned for GDM in the early period.

Conclusion: With screening tests to be applied to risky groups in early pregnancy, a significant number of cases with GDM recently be detected on time. Thereby, maternal and fetal morbidity and mortality rates might be considerably reduced thanks to providing proper treatments and regular monitoring. Furthermore, for obtaining specific data concerning the factors with potential influence on the risk of GDM, further studies on this topic need to be performed.

Keywords: Early screening, gestational diabetes mellitus, oral glucose tolerance test.

\section{INTRODUCTION}

Gestational diabetes mellitus (GDM), defined as diabetes diagnosed during pregnancy, can lead to negative fetal and maternal consequences such as macrosomia, shoulder dystocia, operative delivery, birth injuries, preeclampsia, hemorrhage, and preterm delivery, with raising concerns about this potential impact. ${ }^{[1,2]}$ It has also been found that GDM increases the risk of diabetes that may occur in the post-pregnancy period by 7 times. ${ }^{[2]}$ Most importantly, complications can be reduced thanks to the appropriate treatments given on time to pregnant women diagnosed with GDM with screening and diagnostic tests during pregnancy. ${ }^{[3]}$

A two-digit (100 g oral glucose tolerance test [OGTT] after 50 g OGTT) or single-digit (75 g OGTT) screening/diagnostic test can be made during pregnancy. Today, in many centers, the two-step screening test continues to be used in diagnostic workup. ${ }^{[4]}$

American Association of Obstetrics and Gynecology (ACOG) has recommended screening all pregnant women diagnosed with GDM, usually in the second trimester or early third trimester, between 24 and 28 weeks. ${ }^{[5,6]}$ The increased frequency of undiagnosed Type 2 diabetes during pregnancy has led to pregnant women's screening recommendations, investigating risk factors at the first visit. ${ }^{[6]}$ The International Association of Diabetes in Pregnancy Study Group (IADPSG) has informed that early screening should be determined by that region's conditions and abnormal glucose metabolism. In addition, the ACOG has recommended early screening to undiagnosed Type 2 diabetes groups with relevant risk factors. ${ }^{[7]}$

The American Diabetes Association (ADA) and the ACOG have evaluated people with body mass index (BMI) of $\geq 25 \mathrm{~kg} / \mathrm{m}^{2}, \mathrm{GDM}$ in a previous pregnancy, $\mathrm{HbA1c}$ higher than $5.7 \%(39 \mathrm{mmol} / \mathrm{mol})$, impaired glucose tolerance, high fasting blood glucose (FBG) levels in the previous tests, any first degree relatives with diabetes, and those in high-risk ethnic group (Latin, Asian, African-American), and those with cardiovascular disease, hypertension, HDL of $<35 \mathrm{mg} \mathrm{dl}$, triglyceride of $>250 \mathrm{mg}$ dl, polycystic ovary syndrome, physical inactivation, history of giving birth to a macrosomia baby (>4000 g), and those over 40 years old as being in risk class. If any of these risk factors are present, they recommend an OGTT in early pregnancy. ${ }^{[8,9]}$ Re-screening is also recommended between 24 and 28 weeks to the early screening test negative pregnant women. ${ }^{[7-9]}$ It has been shown that the risk of a congenital anomaly due to hyperglycemia and the risk of diabetic complications (nephropathy and retinopathy) in early pregnancy increases. Therefore, if diabetes can be caught early and given appropriate treatment on time, the risk of complications due to this disease can be significantly reduced in pregnant women. ${ }^{[10,11]}$

Our study aimed to determine the appropriate trimester for gestational diabetes screening, elucidate risk factors, and minimize maternal and fetal morbidity and mortality by recognizing diabetic cases at an earlier stage with an administration of a $50 \mathrm{~g}$ glucose screening test in the first and second trimesters.

\section{MATERIAL AND METHODS}

This study was performed on 153 pregnant women who were admitted to the antenatal clinics of the Turkish Republic Ministry of Health Zeynep Kamil Gynecologic and Pediatric Training and Research Hospital between March 2011 and August 2011. The role of making GDM diagnosis in the early stages of pregnancy was investigated retrospectively by comparing $50 \mathrm{~g}$ OGTT, administered to the same pregnant women both in the first trimester (between $8^{\text {th }}$ and $14^{\text {th }}$ weeks) and the second trimester (between $24^{\text {th }}$ and $28^{\text {th }}$ weeks), values. Pregnant women with a single live pregnancy between $8^{\text {th }}$ and $14^{\text {th }}$ weeks and who had regular follow-up were included in the study. Those with chronic or systemic disease, anomalies detected in their current pregnancy, multiple pregnancies, and pregestational diabetes were excluded from the study. The necessary ethical approval was obtained from our hospital's local ethics committee (decision number: 11).

Pregnancy week was calculated based on the last menstrual period and old and current ultrasonography findings. Pregnant women's anamnesis information at the time of first application was recorded to compare risk factors for GDM, identified in similar studies by the literature scanning. Age, gravida, parity, number of abortions, smoking, a previous GDM history, a family history of DM, a previous history of preeclampsia, a large baby birth history, a previous MFD (dead fetus) history, and a fetal anomaly history were all noted. The pregnant women's BMI was calculated by questioning their height and weight.

Our study's threshold values in OGTT were based on those proposed by Carpenter and Causton (Table 1). 
Table 1: The values proposed by Carpenter and Causton

\begin{tabular}{lcc}
$\begin{array}{l}\text { Plasma glucose } \\
(\mathbf{m g} / \mathbf{d l}) \mathbf{( h )}\end{array}$ & $\begin{array}{c}\mathbf{5 0} \mathbf{~ g} \\
\text { screening test }\end{array}$ & $\begin{array}{c}\mathbf{1 0 0} \mathbf{~ g} \\
\text { diagnostic test }\end{array}$ \\
\hline Hunger & - & $\geq 95$ \\
$1^{\text {st }}$ & $\geq 140$ & $\geq 180$ \\
$2^{\text {nd }}$ & - & $\geq 155$ \\
$3^{\text {rd }}$ & - & $\geq 140$ \\
\hline
\end{tabular}

$50 \mathrm{~g}$ OGTT was applied to all pregnant women between $8^{\text {th }}$ and $14^{\text {th }}$ weeks included in the study. The study patients were divided into two groups as non-GDM and GDM based on venous plasma glucose values measured $1 \mathrm{~h}$ after $50 \mathrm{~g}$ of oral glucose load given to the patient after dissolving in $250 \mathrm{cc}$ water, hungry or full, made at any time of the day. Non-GDM consisted of those with plasma glucose levels $<140$ $\mathrm{mg} / \mathrm{dl}$ (considered normoglycemia) and plasma glucose levels between 140 and $200 \mathrm{mg} / \mathrm{dl}$ (considered abnormal glucose tolerance [AGT]), GDM group plasma glucose levels $\geq 200 \mathrm{mg} / \mathrm{dl}$ (considered GDM).

A $3 \mathrm{~h} 100 \mathrm{~g}$ OGTT was performed on those with AGT after $8 \mathrm{~h}$ of fasting and a proper diet. First, FBG was measured, then venous plasma glucose levels were measured at the $1^{\text {st }} \mathrm{h}, 2^{\text {nd }} \mathrm{h}$, and $3^{\text {rd }} \mathrm{h}$ after $100 \mathrm{~g}$ of glucose dissolved in $250 \mathrm{cc}$ of water were given to patients, followed by they diagnosed as GDM when they had at least two high values. Besides, in those with a single high value, $100 \mathrm{~g}$ OGTT was repeated in the second trimester of pregnancy $\left(24^{\text {th }}-28^{\text {th }}\right.$ weeks); those with at least two high values were diagnosed with GDM, a single high value was diagnosed with AGT. $50 \mathrm{~g}$ OGTT was repeated in the second trimester $\left(24^{\text {th }}-28^{\text {th }}\right.$ weeks) in the non-GDM group when the first trimester $50 \mathrm{~g}$ OGTT detected plasma glucose levels $<140 \mathrm{mg} / \mathrm{d}$; values of $<140 \mathrm{mg} / \mathrm{dl}$ considered normal again. In contrast, we performed an additional $100 \mathrm{~g}$ OGTT on pregnant women with values of $\geq 140 \mathrm{mg} / \mathrm{dl}$ and $<200 \mathrm{mg} / \mathrm{dl}$, then managed them according to the above-mentioned diagnostic criteria; ultimately, we made a diagnosis of GDM in those with blood glucose level $\geq 200 \mathrm{mg} / \mathrm{dl}$. HbA1c value was measured at the time of diagnosis in all pregnant women diagnosed with GDM and AGT. Eventually; results were analyzed and compared between the groups.

\section{Statistical Analysis}

In descriptive statistics of the data, mean, standard deviation, frequency, and ratio values were used. The data distribution was tested with Kolmogorov-Smirnov, and variables were analyzed using Kruskal-Wallis, Mann-Whitney U-test, and independent sample ttest. We performed the Chi-square test to analyze proportional data, the Fischer test when Chi-square conditions were not met. Logistic regression analysis was utilized to investigate the influence levels of variables. Statistical analysis of obtained data was performed using the SPSS 20.0 package program (IBM, Armonk, NY, USA).

\section{RESULTS}

In 22 of 153 pregnant women who were applied $50 \mathrm{~g}$ OGTT in the first trimester, a plasma glucose level $>140 \mathrm{mg} / \mathrm{dl}$ was found. While 22 pregnant women were performed $100 \mathrm{~g}$ OGTT, 7 were diagnosed with GDM. The first and second trimesters $100 \mathrm{~g}$ OGTT values of the remaining 15 pregnant were as follows: Seven were within normal limits, five were diagnosed with GDM by repeating $100 \mathrm{~g}$ OGTT in the second trimester, and three with AGT by repeating $100 \mathrm{~g}$ OGTT in the second trimester, with a single high value. About $4.5 \%$ (7) of all pregnant women were diagnosed with GDM in the first trimester (Table 2).

In the second trimester, pregnant women, 21 of whom had abnormal test results (>140 mg/dl), were with a second trimester gestational week mean of 25.4. Of these 21 pregnant women who were $100 \mathrm{~g}$ OGTT applied, five were diagnosed with GDM, six had a single high value and were diagnosed as AGT, and ten had normal values (normoglycemia). About 6.5\% (10) of a total of 153 pregnant women were diagnosed with GDM in the second trimester.

GDM, diagnosed in $4.5 \%$ (7) in the first trimester and 6.5\% (10) in the second trimester, was detected in $11 \%$ (17) of the pregnant women in the study. About 5.8\% (9) of 153 pregnant women were diagnosed with AGT. The first trimester and second-trimester OGTT screening and diagnostic test results between the study groups are presented in Table 2.

GDM, diagnosed in $41.2 \%$ in the first trimester and $58.8 \%$ second trimester, was found with a higher rate in pregnant women over 30 years $(p=0.000<0.05)$. There was no significant difference in terms of height, weight, BMI values, smoking rates, and $1^{\text {st }}$ measurement weeks between group's non-GDM and GDM ( $p>0.05$ ) (Table 3). Table 3 shows the comparison of risk factors between the study groups.

In GDM group, a previous GDM history ( $p=0.000<0.05)$, a family history of DM $(p=0.019<0.05)$, a previous history of preeclampsia $(p=0.001<0.05)$, and FBG value $(p=0.002<0.05)$ were found with a significantly higher rate than non-GDM group (Table 4).

Table 2: First trimester and second-trimester OGTT screening and diagnostic test results between the study groups

\begin{tabular}{lcc} 
& GDM group & Non-GDM group \\
\cline { 2 - 3 } & $\mathbf{n}$ & $\%$ \\
\hline First trimester 50/100 g OGTT screening results & 7 & 41.2 \\
The first trimester high 50 g OGTT, normal 100 g OGTT, or AGT. Second trimester 100 g OGTT results & 5 & 29.4 \\
Second trimester 50/100 g OGTT screening results & 5 & 29.4 \\
\hline OGTT: Oral glucose tolerance test; GDM: Gestational diabetes mellitus; AGT: Abnormal glucose tolerance. & 126 & \\
\hline
\end{tabular}


Table 3: Comparison of risk factors between the Groups 1 (GDM absent) and 2 (GDM present) in pregnant women

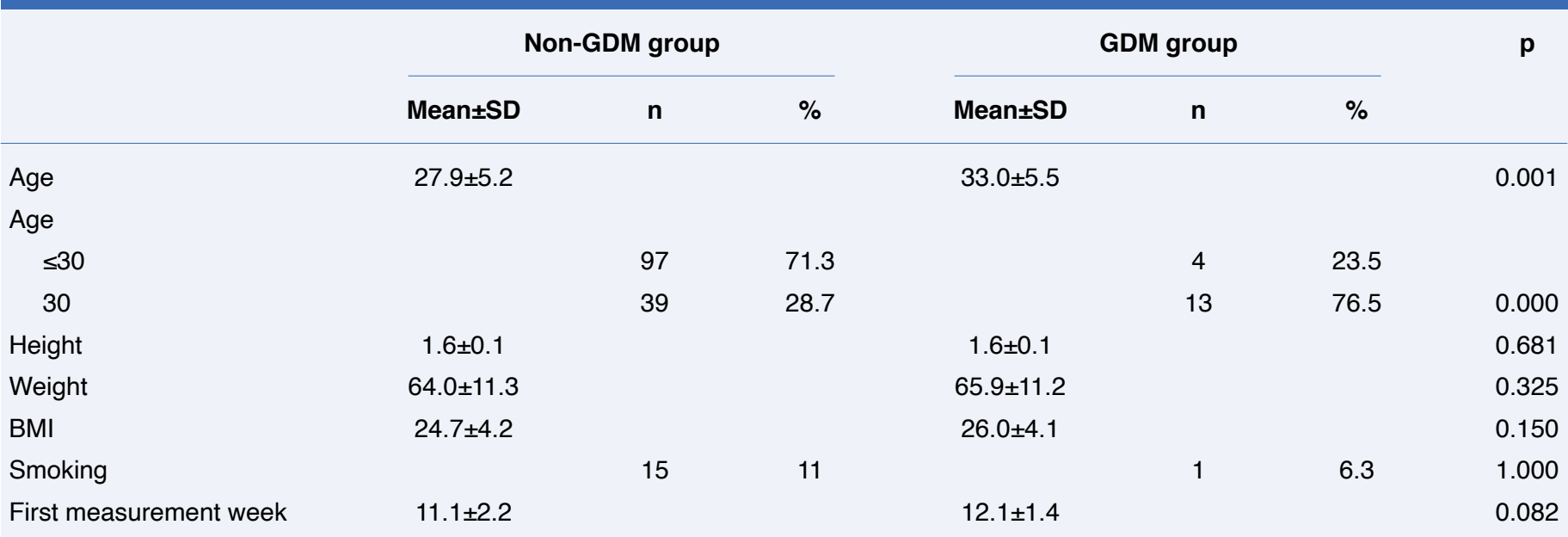

Mann-Whitney U-test/t-test/Chi-square test (fisher test); GDM: Gestational diabetes mellitus; SD: Standard deviation; BMI: Body mass index.

Table 4: Comparison of a previous GDM history, a family history of DM, a previous history of preeclampsia, and FBG value between the study groups

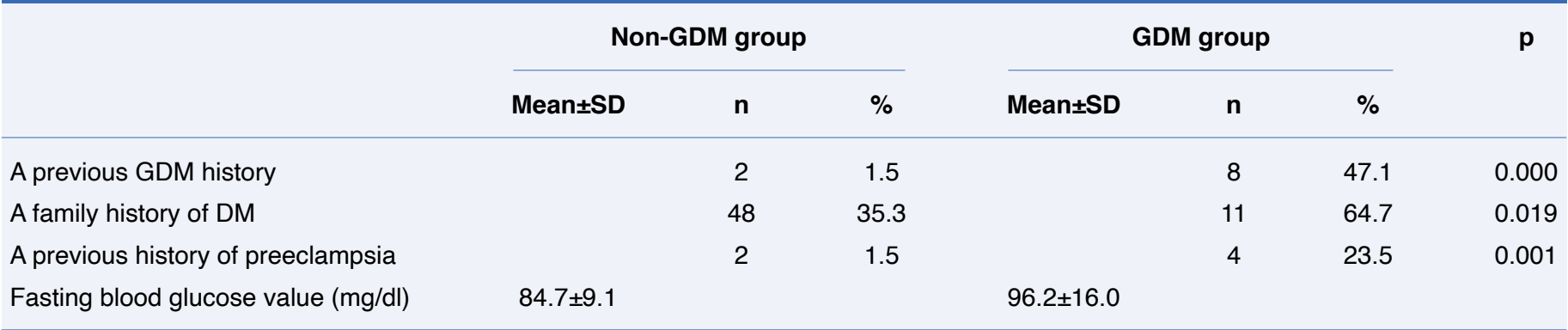

Mann-Whitney U-test/ Chi-square test (fisher test); DM: Diabetes mellitus; FBG: Fasting blood glucose; SD: Standard deviation; GDM: Gestational diabetes mellitus.

It was observed that the number of pregnancies (gravida) and births (parity) was higher in the GDM group than in the non-GDM group. Furthermore, the GDM group tended to have a significantly higher birth rate of large babies $(>4000 \mathrm{~g})$ in the previous pregnancies than the non-GDM group $(p=0.003<0.05)$. The presence and number of abortions, a previous MDF history (dead fetus), and a fetal anomaly history did not significantly differ between groups (Table 5). Comparing the rates of gravida, parity, a large baby birth history, number of abortions, a previous MDF history (dead fetus), and a fetal anomaly history between the study groups are shown in Table 5.

We also compared pregnant women diagnosed with GDM and AGT to those with normoglycemia for the relevant variables, whose results were given below as the following. The mean age, the total number of pregnancies (gravida), number of abortions, number of births (parity), and a previous GDM history in pregnant women with GDM tended to be higher $(p<0.05)$ than both those with normoglycemia and AGT. In those with GDM, the mean parity, a previous history of preeclampsia, a large baby birth history, a family history of $\mathrm{DM}$, and the mean FBG were significantly higher $(p<0.05)$ than those with normoglycemia. None of the variables made a significant difference between the normoglycemic and AGT patients (Table 6). Table 6 presents the analysis of risk factors among pregnant women with GDM, AGT, and normoglycemia.

Taken the effects of risk factors on GDM evaluated with univariate analysis, being over the age of 30 raised the risk of GDM in patients approximately 8 times. While having a family history of DM increased GDM risk in pregnant women by 3.3 times, an FBG level above $87.5 \mathrm{mg} / \mathrm{dl}$ increased approximately 5 times. A previous GDM history emerged as the factor that increased the risk the most and increased GDM risk by about 59 times. Again, a previous history of preeclampsia, one of the crucial diseases complicating pregnancy, also increased the risk of GDM approximately 20 times. A large baby birth history, a more typical result in pregnant women diagnosed with GDM, increased the GDM risk 13.6 times. In addition to these findings, while the gravida number being three and over raised the risk of GDM in pregnant women 6 times, this risk rose approximately 18 times in pregnant women, being multiparous (Table 7). Comparing the effects of risk factors on GDM with univariate analysis is demonstrated in Table 7. 
Table 5: Comparing the rates of gravida, parity, a large baby birth history, number of abortions, a previous MDF (dead fetus) history, and a fetal anomaly history between the study groups

\begin{tabular}{|c|c|c|c|c|c|c|c|}
\hline & \multicolumn{3}{|c|}{ Non-GDM group } & \multicolumn{3}{|c|}{ GDM group } & $\mathbf{p}$ \\
\hline \multicolumn{8}{|l|}{ Gravida } \\
\hline$\leq 2$ & & 98 & 72.1 & & 5 & 29.4 & 0.000 \\
\hline Number of births (parity) & $1.5 \pm 0.6$ & & & $1.9 \pm 0.8$ & & & 0.019 \\
\hline Number of abortions & $1.3 \pm 0.7$ & & & $1.5 \pm 0.8$ & & & 0.593 \\
\hline A large baby birth history & & 3 & 2.2 & & 4 & 23.5 & 0.003 \\
\hline A previous MDF history (dead fetus) & & 3 & 2.2 & & 2 & 11.8 & 0.095 \\
\hline A fetal anomaly history & & 2 & 1.5 & & 1 & 5.9 & 0.299 \\
\hline
\end{tabular}

Mann-Whitney U-test/Chi-square test (fisher test); GDM: Gestational diabetes mellitus; SD: Standard deviation.

Table 6: Analysis of risk factors among pregnant women with GDM, AGT, and normoglycemia

\begin{tabular}{|c|c|c|c|c|c|c|c|c|c|}
\hline & \multicolumn{3}{|c|}{$\begin{array}{l}\text { Pregnant women } \\
\text { with normoglycemia }\end{array}$} & \multicolumn{3}{|c|}{$\begin{array}{l}\text { Pregnant women } \\
\text { with AGT }\end{array}$} & \multicolumn{3}{|c|}{$\begin{array}{l}\text { Pregnant women } \\
\text { with GDM }\end{array}$} \\
\hline & Mean \pm SD & $\mathbf{n}$ & $\%$ & Mean \pm SD & $\mathbf{n}$ & $\%$ & Mean \pm SD & $\mathbf{n}$ & $\%$ \\
\hline Age & $27.9 \pm 5.2^{*}$ & & & $27.9 \pm 5.2^{*}$ & & & $33.0 \pm 5.5$ & & \\
\hline \multicolumn{10}{|l|}{ Age } \\
\hline Height & $1.6 \pm 0.1$ & & & $1.6 \pm 0.0$ & & & $1.6 \pm 0.1$ & & \\
\hline Weight & $63.5 \pm 10.6$ & & & $70.7 \pm 17.6$ & & & $65.9 \pm 11.2$ & & \\
\hline BMI & $24.5 \pm 3.9$ & & & $27.7 \pm 6.9$ & & & $26.0 \pm 4.1$ & & \\
\hline \multicolumn{10}{|l|}{ Gravida } \\
\hline Number of abortions & $1.3 \pm 0.7$ & & & & 0 & 0 & $1.5 \pm 0.8$ & & \\
\hline A previous GDM history & & 2 & $1.6^{*}$ & & 0 & $0.0^{*}$ & & 8 & 47.1 \\
\hline A previous history of preeclampsia & & 2 & $1.6^{*}$ & & 0 & 0.0 & & 4 & 23.5 \\
\hline A large baby birth history & & 3 & $2.4^{*}$ & & 0 & 0.0 & & 4 & 23.5 \\
\hline A previous MDF (dead fetus) history & & 3 & $2.4^{*}$ & & 0 & 0.0 & & 2 & 11.8 \\
\hline A fetal anomaly history & & 2 & 1.6 & & 0 & 0.0 & & 1 & 5.9 \\
\hline Smoking & & 13 & 10.2 & & 2 & 22.2 & & 1 & 5.9 \\
\hline A family history of DM & & 45 & $35.4^{\star}$ & & 3 & 33.3 & & 11 & 64.7 \\
\hline $\mathrm{FBG}(\mathrm{mg} / \mathrm{dl})$ & $84.3 \pm 9.2^{*}$ & & & $89.7 \pm 7.2$ & & & $96.2 \pm 16.0$ & & \\
\hline
\end{tabular}


Table 7: Comparing the effects of risk factors on GDM with univariate analysis

Univariate analysis
OR
\%95 Confidence interval

p

\begin{tabular}{|c|c|c|c|c|}
\hline Age $(>30 / \leq 30)$ & 8.083 & 2.482 & 26.324 & 0.001 \\
\hline A family history of DM & 3.361 & 1.170 & 9.654 & 0.024 \\
\hline FBG (>87,5/s87,5 mg/dl) & 4.935 & 1.528 & 15.935 & 0.08 \\
\hline Gravida $(>3 / \leq 2)$ & 6.189 & 2.043 & 18.752 & 0.001 \\
\hline Parity & 18.000 & 2.322 & 139.564 & 0.006 \\
\hline A previous GDM history & 59.556 & 10.988 & 322.790 & 0.000 \\
\hline A previous history of preeclampsia & 20.615 & 3.441 & 123.515 & 0.001 \\
\hline A large baby birth history & 13.641 & 2.750 & 67.675 & 0.001 \\
\hline
\end{tabular}

Logistic regression, FBG: Fasting blood glucose; GDM: Gestational diabetes mellitus; OR: Odd ratios; DM: Diabetes mellitus.

Table 8: Comparing risk factors among pregnant women diagnosed with GDM by performing $50 \mathrm{~g}$ OGTT in the first trimester and second trimester

GDM

Age

Height

Weight

BMI

Gravida

Parity

Abortion

A previous GDM history

A previous history of preeclampsia

A large baby birth history

A previous MDF (dead fetus) history

A fetal anomaly history

Smoking

A family history of DM

First measurement week

FBG (mg/dl)

First $50 \mathrm{~g}$ OGTT

HbA1c
First trimester

\begin{tabular}{c}
\hline Mean $\pm S D$ \\
$33.6 \pm 5.9$ \\
$1.6 \pm 0.1$ \\
$68.1 \pm 14.5$ \\
$27.4 \pm 5.1$ \\
$3.3 \pm 1.3$ \\
$2.0 \pm 0.6$ \\
$1.3 \pm 0.6$
\end{tabular}

n
$\%$

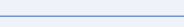

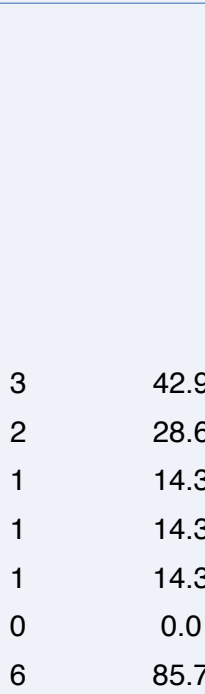

$11.9 \pm 1.2$

$105.9 \pm 18.7$

$170.3 \pm 11.9$

$6.3 \pm 0.6$

Second trimester

p

\begin{tabular}{lll}
\hline Mean \pm SD & n
\end{tabular}

$\begin{array}{cccc}32.6 \pm 5.5 & & & 0.601 \\ 1.6 \pm 0.1 & & & 0.669 \\ 64.3 \pm 8.7 & & & 0.601 \\ 25 \pm 3.2 & & & 0.315 \\ 3.3 \pm 1.5 & & & 0.962 \\ 1.9 \pm 0.9 & & & 0.635 \\ 1.7 \pm 1.2 & & & 1.000 \\ & 5 & 50.0 & 1.000 \\ & 2 & 20.0 & 1.000 \\ & 3 & 30.0 & 0.603 \\ & 1 & 10.0 & 1.000 \\ & 0 & 0.0 & 0.412 \\ 12.2 \pm 1.5 & 1 & 10.0 & 1.000 \\ 89.5 \pm 10.2 & 5 & 50.0 & 0.304 \\ 139.9 \pm 25.9 & & & 0.417 \\ 6.0 \pm 0.3 & & & 0.109 \\ & & & 0.014 \\ & & & 0.364\end{array}$

Mann-Whitney U-test/Chi-square test (fisher test). FBG: Fasting blood glucose; GDM: Gestational diabetes mellitus; DM: Diabetes mellitus; BMI: Body mass index.

$50 \mathrm{~g}$ OGTT values of pregnant women diagnosed with GDM in the first trimester appeared to be significantly higher than those in the second trimester. No other variable values and distributions showed significant differences between pregnant women diag- nosed with GDM in the first trimester and second trimester. Comparing risk factors among pregnant women diagnosed with GDM by performing $50 \mathrm{~g}$ OGTT in the first trimester and second trimester are given in Table 8. 


\section{DISCUSSION}

Seventeen (11\%) of 153 pregnant women in our study were diagnosed with GDM; this rate has been reported about $7 \%$, very variable, in the literature..$^{[8]}$ Our plausible conjecture on this result is that we associated this high GDM diagnosis with our study center being the reference hospital.

The IADPSG has informed that early screening should be determined according to that region's conditions and abnormal glucose metabolism. However, the ADA and ACOG have recommended it to the group with risk factors for undiagnosed Type 2 diabetes. ${ }^{[7]}$ It has also been advocated to screen pregnant women with negative screening tests in early pregnancy again between $24^{\text {th }}$ and $28^{\text {th }}$ weeks. $^{[7-9]}$ In our study, $41.2 \%$ of GDM cases ${ }^{[7]}$ were diagnosed in the first trimester and $58.8 \%(10)$ in the second trimester. In pregnancy, the optimal time interval for screening for GDM is still a controversial issue. As a general hypothesis, insulin sensitivity decreases with advancing gestational age, and insulin resistance increases in cells. Due to this mechanism that develops due to pregnancy's physiological and hormonal changes, advancing pregnancy weeks have been considered more suitable weeks for diagnosing GDM. Therefore, at $24^{\text {th }}-28^{\text {th }}$ weeks of gestation, the glucose screening test has been widely preferred for use. ${ }^{[12]}$

GDM prevalence in the first trimester varies between $1 \%$ and $22 \% .{ }^{[13]}$ Yeral et al., ${ }^{[14]}$ in their study, using FBG, $50 \mathrm{~g}$ glucose twostep screening test, and $75 \mathrm{~g}$ glucose screening test, investigated the rates of GDM detection in the first trimester. It was determined as $5 \%$ in FBG, 6\% in $50 \mathrm{~g}$ double-step screening test, and $10 \%$ in the $75 \mathrm{~g}$ screening test, respectively. In our study, 4,5\% of the pregnant women were diagnosed with GDM with a double-step $50 \mathrm{~g}$ OGTT performed in the first trimester. Dashora et al. ${ }^{[15]}$ aimed to diagnose GDM in the early weeks by applying $75 \mathrm{~g}$ OGTT at 2-month intervals until the $28^{\text {th }}$ week to 564 pregnant women in a high-risk group for GDM. Besides, in $88 \%$ of pregnant women diagnosed with GDM, a GDM diagnosis was made with this method before the $28^{\text {th }}$ weeks.

We used the $50 \mathrm{~g}$ double-step OGTT test in our trial and made a GDM diagnosis in the first trimester in $41.5 \%$ of those diagnosed with GDM. In the study published by Palatnik et al., ${ }^{[16]}$ evaluating 19 thousand pregnant women, perinatal outcomes were evaluated in pregnant women diagnosed with GDM with screening and diagnostic tests at different gestational weeks. In pregnant women who had screening tests in five different groups, including those at $24^{\text {th }}$ $26^{\text {th }}$ weeks, $27^{\text {th }}, 28^{\text {th }}, 29^{\text {th }}$, and at weeks over 30 , it was stated that GDM diagnosis was made more frequently as the gestational week progresses. Approximately $30 \%$ of pregnant women with GDM diagnosis consisted of the group diagnosed at $30^{\text {th }}$ weeks and over; however, no significant difference was found between those diagnosed and treated in earlier weeks and those diagnosed and treated in latter weeks regarding perinatal outcomes. Despite these results, it was striking that pregnant women diagnosed with GDM and treated at an earlier week tended to experience significantly less gestational hypertension and preeclampsia than those who were not. Our research did not assess pregnant women's perinatal outcomes; although the number of cases was small, we could diagnose about $41 \%$ of pregnant women in the early gestational weeks. American Disease Prevention Committee (USPSTF) published their sugges- tions in 2014 that treatment started right after early diagnosis can prevent maternal and fetal complications. ${ }^{[7]}$ Considering that $4.5 \%$ of our study patients and $41.5 \%$ of pregnant women diagnosed with GDM had a GDM diagnosis made in the first trimester, our paper further contributes to the literature by revealing that a significant proportion of GDM diagnoses can be established with screening, especially in a risky group.

It is of high interest to note in the present study that $50 \mathrm{~g}$ first trimester OGTT values of GDM patients differed significantly between those who were diagnosed in the first and second trimesters $(p=0.014)$. Whereas the mean $50 \mathrm{~g}$ OGTT value was $170 \mathrm{mg} / \mathrm{dl}$ in those diagnosed in the first trimester, it was $140 \mathrm{mg} / \mathrm{dl}$ in those diagnosed in the second trimester.

Sesmilo et al., ${ }^{[17]}$ in their studies elucidating the role of the firsttrimester FBG levels in GDM diagnosis and investigating its effects on maternal and perinatal outcomes, reported that when the FBG level rose above $88 \mathrm{mg} / \mathrm{dl}$, the risk of GDM increased 2.5 times. It was also found that pregnant women with a blood glucose level of more than $88 \mathrm{mg} / \mathrm{dl}$ were more likely to have a large baby (>4000 g) birth than those with between 79 and $87 \mathrm{mg} / \mathrm{dl}$. In support of these results, as mentioned above, the HAPO study investigating the negative effects of hyperglycemia on pregnancy suggested that when FBG values were above $95 \mathrm{mg} / \mathrm{dl}$, fetal macrosomia risk increased 4-6 times. ${ }^{[18]}$ Our study revealed that, in the GDM group, the mean FBG level was $96 \mathrm{mg} / \mathrm{dl}$, while this rate was statistically significantly lower in the non-GDM group than the GDM group. Again, looking at a large baby birth history, it was observed at $23 \%$ in the GDM group and $2 \%$ in the non-GDM group. In this sense, having a large baby birth history increased the risk of GDM in pregnant women up to 13 times. In many previous studies, FBG value has been significantly higher in patients with GDM than in those without it. Thus, blood glucose levels must be quickly controlled in the early period to prevent the increase of maternal and fetal complications. Our study also supports that FBG limit values should be taken under control early and withdrawn below $90-95 \mathrm{mg} / \mathrm{dl}$, similar to other studies.

One of the biochemical values auxiliary to diagnosing GDM in the first trimester is HBA1c. Some authors argue that complications due to GDM can be prevented with the initiation of treatment according to the HBA1c values checked in the early period and that GDM can be cured earlier. With defining the values between $5.7 \%$ and $6.4 \%$ as prediabetes, Osmundson et al., ${ }^{[19]}$ in their study evaluating 5700 pregnant women, determined the value of $6.5 \% \mathrm{HBA} 1 \mathrm{c}$ as the limit value in the diagnosis of GDM. Besides, they emphasized that patients' HBA1c values were in the prediabetic range, $29 \%$ of pregnant women who were applied OGTT were diagnosed with GDM, and in those with $\mathrm{HBA} 1 \mathrm{C}$ values lower than $5.4 \%$, this diagnosis rate was identified as $14 \%$. Similarly, in another study conducted in Australia, in those with normal $75 \mathrm{~g}$ OGTT values but HBA1c values higher than $5.9 \%$, GDM development rates were established to be higher in later gestational weeks, and perinatal outcomes were also shown to be negatively affected. ${ }^{[20]}$ In our trial, while the mean of HBA1c value in pregnant women diagnosed with GDM in the first trimester was $6.3 \%$, it was detected as $6 \%$ in those diagnosed in the second trimester, concluding no statistically significant difference existed. We could not compare HBA1c values among the patients with and without GDM because HBA1c values of those without GDM were not 
among our data. However, in line with literature data, we noticed a mean value of $6 \%$ and above in GDM.

This research, additionally, aims to show the effect of risk factors on GDM and elucidate the role of early screening in those with risk factors. In the current study, as the next step, a previous GDM history was found at a rate of $47 \%$ in the GDM group and $1.5 \%$ in the nonGDM group $(p<0.05)$. Schwartz et al., ${ }^{[21]}$ too, in their meta-analysis posted, reported the recurrence rate in those with a previous GDM history as $48 \%$, similar to our data.

The ACOG and the ADA have also recommended early screening by evaluating pregnant women with a previous GDM history as a risky group; these suggestions are compatible with our data and support our study's findings. ${ }^{[8]}$

Another result we put forward is that a previous history of preeclampsia significantly increases the risk of GDM approximately 20 times $(p=0.001)$, with being seen in the GDM group as $23.5 \%$, while in the non-GDM group as $1.5 \%$. In a study by Lee et al. ${ }^{[22]}$ in 2017 , in pregnant women with preeclampsia in previous pregnancies, the GDM detection rate in subsequent pregnancies was higher, similar to our study.

When we look at the gravida-parity rates in the GDM group, we found gravida and parity rates to be higher than those in the nonGDM group, similar to the literature. ${ }^{[23]}$

In the present study, while a family history of diabetes mellitus was detected in $64.7 \%$ of pregnant women in the GDM group, this rate was $35.3 \%$ in those in the non-GDM group ( $p=0.019)$. Similarly, the research conducted by $\mathrm{Kim}$ et al. ${ }^{[24]}$ on 4500 women showed that the presence of a diabetes history in any first-degree relative increased the risk of GDM by 3-7 times.

As a result, about half of the pregnant women with GDM have been diagnosed in the first trimester, with the ideal time remains a controversial issue in screening for GDM. If pregnant women, especially in the risk group, could be diagnosed by performing OGTT in the early period, we strongly consider that fetal and maternal morbidity and mortality would be prevented. This article, therefore, provides some critical knowledge and insights into the literature on GDM screening in early pregnancy and an overview of the published scientific evidence within this crucial research field. However, due to its retrospective nature and a relatively small number of cases, it is clear that our study results should be interpreted with caution and enlightened with further and more extensive, prospective clinical studies, shedding light on this topic.

\section{Statement}

Ethics Committee Approval: The Zeynep Kamil Women and Children Diseases Training and Research Hospital Research Ethics Committee granted approval for this study (date: 20.07.2012, number: 11).

Informed Consent: Written informed consent was obtained from patients who participated in this study.

Peer-review: Externally peer-reviewed.

Author Contributions: Concept - HT, EK; Design - HT; Supervision - EK, EÇ; Resource - EK, EÇ, HT; Materials - EK, EÇ, HT; Data Collection and/or Processing - HT, ZB, SE; Literature Search - HT, ZB, SE; Writing - HT, ZB; Critical Reviews - EK, EÇ.
Conflict of Interest: The authors have no conflict of interest to declare.

Financial Disclosure: The authors declared that this study has received no financial support.

\section{REFERENCES}

1. American Diabetes Association. (2) Classification and diagnosis of diabetes. Diabetes Care 2015;38:S8-16.

2. Wojtyla C, Stanirowski P, Gutaj P, Ciebiera M, Wojtyla A. Perinatal outcomes in a population of diabetic and obese pregnant women-the results of the polish national survey. Int $\mathrm{J}$ Environ Res Public Health 2021;18(2):560.

3. Lohse N, Marseille E, Kahn JG. Development of a model to assess the cost-effectiveness of gestational diabetes mellitus screening and lifestyle change for the prevention of Type 2 diabetes mellitus. Int J Gynaecol Obstet 2011;115(1):S20-5.

4. Palatnik A, Swanson K, Churchill T, Bilski A, Grobman WA, Miller ES. Association between type of screening for gestational diabetes mellitus and cesarean delivery. Obstet Gynecol 2017;130(3):539-44.

5. Danilenko-Dixon DR, van Winter JT, Nelson RL, Ogburn PL Jr. Universal versus selective gestational diabetes screening: Application of 1997 American diabetes association recommendations. Am J Obstet Gynecol 1999;181(4):798-802.

6. Aziz NL, Abdelwahab S, Moussa M, Georgy M. Maternal fructosamine and glycosylated haemoglobin in the prediction of gestational glucose intolerance. Clin Exp Obstet Gynecol 1992;19(4):235-41.

7. Moyer VA, U.S. Preventive Services Task Force. Screening for gestational diabetes mellitus: U.S. Preventive Services Task Force recommendation statement. Ann Intern Med 2014;160(6):414-20.

8. ACOG practice bulletin No. 190: Gestational diabetes mellitus. Obstet Gynecol 2018;131(2):e49-64.

9. American Diabetes Association. 2. Classification and diagnosis of diabetes: Standards of medical care in diabetes-2020. Diabetes Care 2020;43(1):S14-31.

10. Schaefer UM, Songster G, Xiang A, Berkowitz K, Buchanan TA, Kjos SL. Congenital malformations in offspring of women with hyperglycemia first detected during pregnancy. Am J Obstet Gynecol 1997;177(5):1165-71.

11. Sheffield JS, Butler-Koster EL, Casey BM, McIntire DD, Leveno KJ. Maternal diabetes mellitus and infant malformations. Obstet Gynecol 2002;100(1):925-30.

12. Moore TR, Hauguel-de Mouzon S, Catalano P. Diabetes in pregnancy. In: Creasy RK, Resnik R, editors. Maternal-Fetal Medicine: Principles and Practice. Philadephia, PA: WB Saunders; 2014. p. 998-1021.

13. Immanuel J, Simmons D. Screening and treatment for early-onset gestational diabetes mellitus: A systematic review and meta-analysis. Curr Diab Rep 2017;17(11):115.

14. Yeral MI, Ozgu-Erdinc AS, Uygur D, Seckin KD, Karsli MF, Danisman AN. Prediction of gestational diabetes mellitus in the first trimester, comparison of fasting plasma glucose, two-step and one-step methods: A prospective randomized controlled trial. Endocrine 2014;46(3):512-8.

15. Dashora U, Dashora V, Kennedy L. Two-hour 75-g oral glucose tolerance test early in pregnancy detects most cases of gestational diabetes. Diabetes Care 2002;25(4):803; author reply 804.

16. Palatnik A, Mele L, Landon MB, Reddy UM, Ramin SM, Carpenter MW, et al. Timing of treatment initiation for mild gestational diabetes mellitus and perinatal outcomes. Am J Obstet Gynecol 2015;213(4):560.e1-8.

17. Sesmilo G, Prats P, Garcia S, Rodríguez I, Rodríguez-Melcón A, Berges 
I, et al. First-trimester fasting glycemia as a predictor of gestational diabetes (GDM) and adverse pregnancy outcomes. Acta Diabetol 2020;57(6):697-703.

18. Coustan DR, Lowe LP, Metzger BE, Dyer AR, International Association of Diabetes and Pregnancy Study Groups. The hyperglycemia and adverse pregnancy outcome (HAPO) study: Paving the way for new diagnostic criteria for gestational diabetes mellitus. Am J Obstet Gynecol 2010;202(6):654.e1-6.

19. Osmundson SS, Zhao BS, Kunz L, Wang E, Popat R, Nimbal VC, et al. Palaniappan LP. First trimester hemoglobin A1c prediction of gestational diabetes. Am J Perinatol 2016;33(10):977-82.

20. Rowan JA, Budden A, Sadler LC. Women with a nondiagnostic $75 \mathrm{~g}$ glucose tolerance test but elevated $\mathrm{HbA} 1 \mathrm{c}$ in pregnancy: An additional group of women with gestational diabetes. Aust N Z J Obstet Gynaecol
2014;54(2):177-80.

21. Schwartz N, Nachum Z, Green MS. The prevalence of gestational diabetes mellitus recurrence--effect of ethnicity and parity: A metaanalysis. Am J Obstet Gynecol 2015;213(3):310-7.

22. Lee J, Ouh YT, Ahn KH, Hong SC, Oh MJ, Kim HJ, et al. Preeclampsia: A risk factor for gestational diabetes mellitus in subsequent pregnancy. PLoS One 2017;12(5):e0178150.

23. Pedersen J, Pedersen LM, Andersen B. Assessors of fetal perinatal mortality in diabetic pregnancy. Analysis of 1,332 pregnancies in the Copenhagen series, 1946-1972. Diabetes 1974;23(4):302-5.

24. Kim C, Liu T, Valdez R, Beckles GL. Does frank diabetes in first-degree relatives of a pregnant woman affect the likelihood of her developing gestational diabetes mellitus or nongestational diabetes? Am J Obstet Gynecol 2009;201(6):576.e1-6. 